Núm. 21-Enero 2020, pp. 99-121

[En línea] http://www.revistas.uma.es/index.php/rejie

\title{
LA CAPACITACIÓN DEL TÉCNICO EN PREVENCIÓN DE RIESGOS LABORALES EN RELACIÓN A LA EDUCACIÓN Y FORMACIÓN COMO INDICADOR DE LA CULTURA PREVENTIVA
}

The training of the technician in occupational health and safety in relation to
education and training as an indicator of the culture of prevention

Recibido: 5 de septiembre de 2019

Aceptado: 26 de noviembre de 2019

Tomás García Aranda

Doctorando en Ciencias jurídicas y sociales

0610265257@uma.es

Universidad de Málaga

\section{RESUMEN}

La capacitación de los profesionales de la prevención de riesgos laborales ha de estar en consonancia con la alta responsabilidad que se deriva de sus funciones y de la naturaleza del bien jurídico que gestionan como es la seguridad y la salud de los trabajadores. Dicha capacitación exige una adecuada formación acorde a la complejidad de sus funciones que les permita enfrentarse a éstas en las mejores condiciones y con las mayores garantías. La puesta en valor de dicha formación $y$, por extensión, su inclusión en todos los niveles del sistema educativo facilitará la consolidación de la cultura de la prevención no sólo en el entorno laboral, sino también en el imaginario colectivo, en todos los ámbitos y sectores de la sociedad, en todos los sujetos activos y pasivos, que puedan intervenir o padecer en algún momento en la gestación, implantación y asimilación de dicha cultura.

\section{PALABRAS CLAVES}

Educación; educación, formación de acceso, capacitación, técnico superior en prevención de riesgos laborales, cultura preventiva.

\begin{abstract}
The training of occupational risk prevention professionals must be in line with the high responsibility that derives from their functions and the nature of the legal good they manage, such as the safety and health of workers. This training requires adequate training according to the complexity of their functions that allows them to face them in the best conditions and with the greatest guarantees. The enhancement of such training and, by extension, its inclusion at all levels of the education system will facilitate the consolidation of the culture of prevention not only in the work environment, but also in the collective imagination, in all areas and sectors of society, in all active and passive subjects, who may intervene or suffer at some time in the gestation, implementation and assimilation of this culture.
\end{abstract}

\section{KEYWORDS}

Education, access training, training, advanced technician in occupational safety and health, preventive culture. 
Sumario: 1. Introducción. 2. Regulación formativa de acceso para el Técnico Superior en Prevención de Riesgos Laborales. 2.1. Niveles formativos y especialidades preventivas necesarios. 2.2. Funciones de los técnicos en prevención de riesgos laborales. 2.3. Evolución de los requisitos formativos de acceso para los técnicos en prevención de riesgos laborales. 2.3.a). Requisitos formativos de acceso a fecha de publicación de la LPRL al amparo del Apartado 1 de la Disposición Adicional Quinta del RSP. 2.3.b). Requisitos formativos de acceso durante el año 1998 al amparo del Apartado 2 de la Disposición Adicional Quinta del RSP. 2.3.c). Requisitos formativos de acceso al amparo de la Disposición Transitoria Tercera del RSP antes de la entrada en vigor del Real Decreto 337/2010. 2.3.d). Requisitos formativos de acceso después de la entrada en vigor del Real Decreto 337/2010, a partir del 24 de marzo de 2010. 3. Conclusiones.

\section{Introducción.}

El colectivo de agentes que participan en la integración de la prevención de riesgos laborales (en adelante PRL) en una organización empresarial está formado por el empresario que dirige dicha organización, los trabajadores y sus representantes, el personal designado para el desempeño de funciones preventivas y los técnicos del servicio de prevención. Quizás sean estos últimos, los técnicos prevencionistas (especialmente los técnicos superiores en prevención de riesgos laborales), los que se encuentran en una posición más vulnerable y sufren en mayor medida las consecuencias de una pobre cultura preventiva en su empresa, por su alta responsabilidad. A pesar de dicha responsabilidad, estos técnicos no disponen de autoridad para tomar decisiones de mando que les permita actuar sobre el resto de trabajadores.

En efecto, la figura del técnico de prevención se encuentra en un terreno intermedio entre las obligaciones del empresario y los derechos de los trabajadores. Por un lado, como técnico del servicio de prevención que apoya al empresario en la implantación de la prevención, a veces actúa inadecuadamente por delegación de éste, arrogándose a sí mismo competencias y obligaciones que corresponden al empresario y, en consecuencia, asumiendo responsabilidades, que si bien en un principio, puede facilitarle su trabajo al brindarle una capacidad ejecutora en sus actuaciones, también le puede suponer un problema en tanto a las graves consecuencias que se puedan derivar de dichas actuaciones a través de riesgos incontrolados, contingencias profesionales y conflictos de intereses entre empresario y trabajador ${ }^{1}$. Entendemos que este profesional, al actuar apoyando técnicamente al empresario, a veces, puede ser percibido por el trabajador y sus representantes como una figura ajena a ellos que actúa por intereses de la empresa y que no siempre tiene entre sus prioridades al trabajador como centro de la política de seguridad y salud de la empresa.

Por otro lado, el técnico de prevención, en su papel de trabajador, bien de la propia empresa dentro de su servicio de prevención propio, bien de la empresa que actúa como servicio de prevención ajeno, no se encuentra en el mismo nivel de obligaciones y responsabilidades que el resto de los trabajadores. Esto se debe a que el técnico actúa como oposición y limite al poder unilateral del empresario, priorizando en sus actuaciones criterios de seguridad y salud laborales frente a otros como la productividad, lo que le lleva a una exposición frente al empresario que no tiene el resto de trabajadores. Dicha

\footnotetext{
${ }^{1}$ Vid. PÉREZ MERLOS, R., MARTÍNEZ CORRAL, C. Y RUIZ CALABRAVA R. (2016). Intereses básicos y resolución de conflictos de las principales figuras en materia preventiva. Valencia: Tirant lo Blanch, pp. 61-62.
} 
exposición, en algunos casos, supone para el técnico de prevención un riesgo importante sobre su persona, con consecuencias tan graves como los derivados de la responsabilidad por sus actuaciones técnicas en materia preventiva (ej.: evaluación de riesgos), al no actuar siempre en sintonía con las expectativas y cultura preventiva del empresario, lo que puede suponer para éste la tentación de abusar de su condición jerárquica imponiendo sus criterios acudiendo si es preciso a coacciones, intimidación y represalias, directamente o a través de terceros, mediante medidas de acoso laboral además de las disciplinarias $^{2}$ en forma de sanciones o incluso de despido por causas objetivas o por una sospechosa y sobrevenida «inaptitud del técnico» ${ }^{3}$ declarada por los servicios de vigilancia de la salud o la mutua de accidentes y enfermedades profesionales.

Como trabajador, el técnico de prevención no tiene una protección de sus derechos acorde a la alta responsabilidad y exposición que tiene en el desempeño de sus funciones, más allá de las mismas garantías que disfrutan los representantes de los trabajadores (arts. 68, a), b) y c) y 56.4 del Real Decreto Legislativo $2 / 2015^{4}$, de 23 de octubre, que aprueba el Texto Refundido de la Ley del Estatuto de los Trabajadores ${ }^{5}$ (en adelante TRLET). En este punto, el técnico de prevención cuenta con varias opciones para ejercer su defensa frente al empresario que le acosa. Una de ellas es acudir a los representantes de los trabajadores (a esos mismos a los que asesora en materia de prevención). Otra opción es instar la activación del Protocolo de Acoso Laboral en el caso de que éste exista; esta vía puede resolverse mediante un acuerdo entre las partes, la intervención del Comité de Seguridad y Salud, o una resolución de la Inspección de Trabajo, o resolución judicial.

${ }^{2}$ Ibid., pp. 62-63.

${ }^{3}$ Existe abundante jurisprudencia al respecto, de la que señalamos las siguientes sentencias:

- Sentencia 795/2006 de 1 de julio de 2006 del Tribunal Superior de Justicia de la Comunidad de Murcia, Sala de lo Social, sobre readmisión y condena por mala fe por la negativa de la condición de trabajador designado por parte de la empresa.

- Sentencia 898/2009 de 4 de diciembre de 2009 del Tribunal Superior de Justicia de Madrid, Sala de lo Social, sobre la readmisión de técnico de servicio de prevención propio.

- Sentencia 520/2010 de 29 de junio de 2010 del Tribunal Superior de Justicia de Cantabria, Sala de lo Social, sobre la readmisión de responsable técnico de prevención en su consideración como trabajador designado.

- Sentencia 2502/2013 de 20 de diciembre de 2013 del Tribunal Superior de Justicia de Asturias, Sala de lo Social, sobre la readmisión en despido por causas económicas, técnicas, organizativas o de producción.

- Sentencia 353/2014 de 25 de abril de 2014 del Tribunal Superior de Justicia de Madrid, Sala de lo Social, sobre prioridad de permanencia, readmisión o indemnización y salarios de tramitación por despido improcedente de técnico del servicio de prevención propio.

- Sentencia de 18 de julio de 2014 del Tribunal Supremo, Sala de lo Contencioso, sobre prioridad de permanencia en ERE y despido del personal del servicio de prevención.

- Sentencia 392/2014 de 2 de octubre de 2014 del Juzgado de lo Social no 41 de Madrid, sobre la readmisión tras un despido por no aptitud sobrevenida no concurriendo causa y la inclusión del trabajador en el servicio de prevención a pesar de la negativa de la empresa.

${ }^{4}$ Estas garantías consisten en la apertura de expediente contradictorio en el supuesto de sanciones por faltas graves o muy graves, en la prioridad de permanencia respecto a los demás trabajadores en los supuestos de suspensión o extinción por causas tecnológicas o económicas, en el derecho a no ser despedido ni sancionado durante el ejercicio de sus funciones ni dentro del año siguiente a su mandato ni ser discriminado en su promoción económica o profesional en razón de su desempeño, y en el derecho de opción del trabajador en caso de despido improcedente a optar entre la readmisión obligatoria para la empresa o la indemnización teniendo derecho en ambas opciones a los salarios de tramitación.

${ }^{5}$ Real Decreto Legislativo 2/2015, de 23 de octubre, que aprueba el Texto Refundido de la Ley del Estatuto de los Trabajadores. (BOE n⿳ 255, 24-10-2015). 
También puede optar por acudir a la Inspección de Trabajo y Asuntos Sociales. Y por último, puede optar por acudir a la vía judicial.

Hay que decir que, al contrario de lo que ocurre en otras profesiones, la del técnico de prevención, es una profesión no regulada. En este sentido, los Técnicos Superiores de Prevención de Riesgos Laborales (en adelante TSPRL), como colectivo, sólo cuentan con un colegio profesional propio en toda España (en la Comunidad Valenciana ${ }^{6}$ ), y que recientemente ha visto como se aprobaba un segundo Convenio Colectivo ${ }^{7}$ que sólo los incluye parcialmente ${ }^{8}$ y que apenas entra en detalle en sus condiciones específicas propias de trabajo más allá de encuadrarlos en un grupo profesional y en un nivel retributivo 9 .

\section{Regulación formativa de acceso para el Técnico Superior en Prevención de Riesgos Laborales.}

Desde que entró en vigor la Ley 31/1995, de 8 de noviembre, de Prevención de Riesgos Laborales ${ }^{10}$, (en adelante LPRL), y su desarrollo parcial mediante el Real Decreto 39/1997, de 17 de enero, por el que se aprueba el Reglamento de los Servicios de Prevención ${ }^{11}$ (en adelante RSP), ha existido una muy variada oferta formativa de acceso a esta cualificación técnica, con diferentes calidades tanto en sus contenidos formativos como en la regulación de éstos ${ }^{12}$, que ha permitido acceder a esta profesión desde perfiles formativos muy diferentes entre si, a veces sin ninguna afinidad con la materia preventiva o no respaldado por una formación complementaria que lo enlace, lo que puede suponer, más allá de una hipotética fortaleza por su transversalidad de contenidos, su devaluación por una programación de éstos inconexa, deficiente o con prioridades en su diseño ajenas a la propia PRL.

\footnotetext{
${ }^{6}$ Ley 1/2009, de 26 de marzo, de la Generalitat, de creación del Colegio Oficial de Técnicos Superiores en Prevención de Riesgos Laborales de la Comunitat Valenciana. (DOCV n ${ }^{\circ}$ 5983, 27 de marzo de 2009 y BOE ${ }^{\circ}$ 91, de 14 de abril de 2009).

${ }^{7}$ Resolución de 21 de septiembre de 2017, de la Dirección General de Empleo, por la que se registra y publica el II Convenio colectivo nacional de servicios de prevención ajenos. (BOE $\mathrm{n}^{\circ} 242$, de 7 de octubre de 2017). Este Convenio sucede a la Resolución de 20 de agosto de 2008, de la Dirección General de Trabajo, por la que se registra y publica el I Convenio colectivo nacional de los Servicios de Prevención Ajenos (BOE n⿳⺈ 220, de 11 de septiembre de 2008).

${ }^{8}$ Según el art. 1 del Convenio, éste «es de aplicación en todo el territorio del Estado Español para aquellas empresas y plantillas encuadradas en el ámbito funcional y personal en los términos definidos en los artículos siguientes...». Es decir, este Convenio se aplica sólo a servicios de prevención ajenos, y en el caso de empresas que se dediquen a otras actividades además de las propias de un servicio de prevención ajeno, se aplicará sólo a las personas que desarrollen de manera preeminente actividades y/o funciones propias del servicio de prevención ajeno. Se excluyen de este Convenio las actividades de formación, asesoría y consultoría no reguladas en el art. 20 del RSP, y las actividades relacionadas con la auditoría en materia preventiva. Tampoco se incluyen las personas que realicen una actividad «que se limite, pura y simplemente, al mero desempeño del cargo de consejero o miembro de los órganos de administración en las empresas que revistan la forma jurídica de sociedad y siempre que su actividad en la empresa solo comporte la realización de cometidos inherentes a tal cargo» y las que sometidas a las relaciones laborales de carácter especial señaladas en el art. 2 del TRLET.

${ }^{9}$ En este Convenio los médicos especialistas en Medicina del Trabajo se adscriben al grupo profesional 1 , nivel retributivo 1, mientras el personal TSPRL y el personal de enfermería especialista en Enfermería del Trabajo se adscriben al grupo profesional II, nivel retributivo 3.

10 La LPRL fue publicada en BOE $n^{\circ} 269$, de 10 de noviembre de 1995, entrando en vigor a los tres meses después de dicha publicación.

${ }^{11}$ El RSP fue publicado en BOE $n^{\circ}$ 27, de 31 de enero de 1997, entrando en vigor a los dos meses de dicha publicación, a excepción del apartado 2 del art. 35, que lo hizo a los doce meses, y de los apartados 2 de los arts. 36 y 37, que lo hicieron el 31 de diciembre de 1998.

${ }^{12}$ Esta afirmación será desarrollada y justificada en los siguientes epígrafes de este trabajo.
} 
En este sentido, la preparación formativa que capacita para ejercer esta profesión técnica, a pesar de haber pasado más de 20 años de la entrada en vigor del RSP que regula sus contenidos mínimos formativos de acceso, y de las posteriores modificaciones que éste ha sufrido, no ha servido para valorar como se merece esta formación, la cual aún continua en un estado de transitoriedad como señala García Jiménez ${ }^{13}$. Esta situación de la formación preventiva ocurre a pesar de la importancia del máximo bien jurídico que protege como es el derecho a la vida, a la integridad física y moral, y a la protección de la salud, regulados en los arts. 15 y 43 de nuestra Carta Constitucional, sin olvidar la referencia que ésta hace al derecho al trabajo regulado en su art. 35 y su exigencia a los poderes públicos para velar por la seguridad e higiene como exigencia inherente a la dignificación de tal derecho en su art. 40.

A pesar de la alta capacitación que se exige al técnico superior de prevención por su elevada responsabilidad, la formación que le capacita, a lo más que ha llegado en estos 20 años ha sido a la actual configuración en másteres de 1 o 2 años, cuya aparición se debe más a necesidades comerciales que a la propia demanda de estos profesionales en el mercado actual, al que desembocan demasiadas veces con escasa experiencia y con una formación poco especializada. En línea con lo señalado por algunos autores como Igartua Miró $^{14}$ y García Jiménez ${ }^{15}$, entendemos que es preciso que la cada vez mayor oferta académica existente en materia preventiva ha de estar acompañada de una mejora en la calidad de contenidos frente a la actual remercantilización ${ }^{16}$ de la adquisición de competencias en la impartición de esta formación. A este proceso de mejora ha de sumarse además el verdadero compromiso de los poderes públicos en el diseño de programas educativos y formativos creíbles y exigentes para esta materia, que entendemos se merece como tal una titulación específica de grado en vez de un postgrado, la cual ni siquiera cumple su función como estudios de especialización. Porque entendemos que difícilmente se puede especializar a un titulado universitario con una formación a veces tan remotamente afín a la prevención cuando accede a este mercado sin tener validadas no ya académicamente sino, al menos, con una experiencia demostrable y acreditable, unas mínimas bases jurídicas, técnicas, científicas o culturales en prevención como herramientas necesarias para especializarse en esta materia. Es imposible especializarse en algo de lo que no se tienen unos conocimientos básicos. Con la actual regulación académica formativa, estos estudios de postgrado se convierten en una formación excesivamente genérica al tener que emplear buena parte de sus contenidos en sentar las bases que ya se le suponían al aspirante a técnico de prevención en su formación y experiencia anteriores. Contenidos que se podrían dedicar a una verdadera profundización y «especialización» no ya teórica sino también verdaderamente práctica.

Quizás habría que plantearse en este punto, sino es mejor optar, en vez de por un postgrado como solución formativa a esta materia, por un grado como existe en otras titulaciones a las que no desmerece por su amplitud de contenidos formativos necesarios

13 GARCÍA JIMÉNEZ, M. (2016). Luces y sombras de la formación en materia de prevención de riesgos laborales: Balance crítico y claves para una reforma. En C. MOLINA NAVARRETE, M. GARCÍA JIMÉNEZ Y M. SORIANO SERRANO (DIRS.). Ley de Prevención de Riesgos Laborales: Una revisión crítica, veinte años después. Madrid: Centro de Estudios Financieros, pp. 129-134.

${ }^{14}$ Vid. IGARTUA MIRÓ, M.T. (2014). Los másteres universitarios «oficiales»: luces y sombras en su implantación y en el proceso de enseñanza-aprendizaje. En AA.VV. Calidad de la docencia universitaria y encuestas: balance del Plan Bolonia, pp. 97-136.

${ }^{15}$ GARCÍA JIMÉNEZ. Op. cit., p. 134.

${ }^{16}$ Ibidem. En alusión a la mercantilización ya existente en la etapa anterior a 2010 donde las competencias en la impartición de esta formación pertenecían a entidades acreditadas por la autoridad laboral. 
para ejercer esta profesión ni por la alta responsabilidad por el bien jurídico con el que trata. Nadie se cuestiona que un médico necesite unos estudios universitarios que antes tenían una duración de seis años y ahora no bajan de cinco, sin considerar los cursos de especialización de prácticas en centros hospitalarios. En este sentido, habría que recordar que la PRL tiene entre su razón de ser la integridad, la salud, la seguridad y el bienestar de las personas. Este planteamiento nos conducirá a una serie de reflexiones e interrogantes en los siguientes párrafos.

En este contexto, podemos cuestionarnos si quizás ésta situación de la formación preventiva de nivel superior se deba a que no se considera que estos estudios han de tener la misma entidad que otras titulaciones técnicas o jurídicas, como la ingeniería, arquitectura, medicina, psicología, biología, químicas, derecho o graduado social, por citar algunas de las más afines y contempladas en los contenidos formativos exigidos por la normativa actual para ejercer como TSPRL. También podemos debatir si quizás incide negativamente en esta situación desfavorable de la formación preventiva superior el no disponer de una planificación y programación propias y uniformes en sus contenidos formativos, con carácter de titulación de grado universitario en vez de los actuales estudios de especialización de máster universitario, a cuyas especialidades preventivas se puede acceder desde todo el espectro de titulaciones universitarias ${ }^{17} \sin$ filtro alguno y con programaciones de contenidos formativos tan diversas y dispersas, regidos por intereses nada que ver con la PRL, hasta el punto de que a veces no cuentan con una sola asignatura en su programación académica que permita facilitar o enlazar con las herramientas básicas necesarias para poder, no ya especializarse, sino al menos comprender los conceptos básicos de la PRL.

Aunque también podemos plantearnos si a esta situación desfavorable no ha contribuido además el hecho de que la disciplina preventiva haya sido de las últimas en incorporarse al mercado laboral y por tanto universitario, lo cual le ha supuesto ser la «cenicienta» que se tiene que hacer hueco entre sus «hermanas mayores», que prefieren «mirar para otro lado» en vez buscar puntos de encuentro en el ámbito académico que aproveche y oriente eficaz y coordinadamente los recursos académicos ya existentes de otras titulaciones académicas más veteranas. En este estado de cosas, entendemos que es necesario cuestionar si no existe una falta de dinamismo en el mundo académico el cual no responde con la rapidez demandada por los cambios políticos, sociales, productivos, económicos, tecnológicos, científicos y jurídicos que inciden directamente en el mercado laboral, que plantean nuevas cuestiones y retos a tratar en el ámbito de la seguridad y salud laborales, y que la Universidad debiera resolver como esencia de su razón de ser, anticipándose en el análisis y búsqueda de soluciones a los problemas reales que le plantea la sociedad.

Como reflexión final y que resume las reflexiones anteriores sobre las posibles causas desde el punto de vista académico que pueden explicar la actual situación de la formación preventiva, nos planteamos si en dicho ámbito académico (desde los niveles inferiores educativos hasta los superiores universitarios), nos encontramos con una cultura preventiva pobre y muy mejorable, lastrada por una falta de sensibilidad y comprensión de la verdadera dimensión de la problemática de la seguridad y salud en el ámbito laboral.

\footnotetext{
${ }^{17}$ Esto ocurre con las especialidades propias del personal TSPRL, es decir, Seguridad en el Trabajo, Higiene Industrial, Ergonomía y Psicosociología aplicada. No ocurre así con la especialidad de Medicina del Trabajo, a la cual sólo es posible acceder desde la titulación de Medicina (Orden SCO/1526/2005, BOE $\mathrm{n}^{\circ} 127$, de 28 de mayo de 2005), ni con la especialidad de Enfermería del Trabajo, para la cual es necesaria la titulación de diplomado o graduado en Enfermería (Orden SAS/1348/2009, BOE nº 129, de 28 de mayo de 2009).
} 
Se podría argumentar que la evolución de los requisitos formativos de acceso al ejercicio de TSPRL, especialmente en sus etapas más tempranas tras la aprobación de la LPRL, se justifica, por una parte, ante la obligatoriedad de contar con estos técnicos por parte de las empresas, por la alta demanda impuesta por la nueva norma preventiva y, por otra parte, por la escasa oferta inicial de estos técnicos ${ }^{18}$. Eso podría explicar que en un principio esta formación estuviera fuera del catálogo de titulaciones universitarias. A pesar de transcurrir más de 20 años desde la entrada en vigor del RSP, la programación actual de los contenidos formativos para el acceso al ejercicio de las funciones preventivas de nivel superior se reducen a un máster de 1 o 2 años, cuando entendemos que quizás habría que plantearse si no es necesario ampliarlos a unos estudios de mayor duración como el grado, y si se quiere, complementados, pero no sustituidos, con un máster de especialización en áreas muy concretas de la materia preventiva.

La educación no es diferente en su análisis y diagnóstico a otros ámbitos que inciden en la PRL, al tratar de explicar dónde y por qué falla el modelo de la prevención en España, a pesar de contar con una legislación y desarrollo normativo prolíficos en esta materia en relación a los países más avanzados y con menores índices de siniestralidad laboral. Entendemos que el diagnóstico es una falta de cultura preventiva en la educación $\mathrm{y}$ en la formación, a todos los niveles y en todos los agentes que intervienen en ella. Sus síntomas no sólo se detectan en unos mejorables índices de siniestralidad laboral sino en el amplio margen de mejora en la capacitación de los profesionales que intervienen en la reducción de estos índices con mayor o menor éxito a pesar de todos los inconvenientes del modelo preventivo actual. A conclusiones parecidas llegó el Informe Durán (2001) ${ }^{19}$ al analizar la formación y educación en el modelo preventivo en España. Por tanto, en el análisis del factor educativo y de su derivada en la formación como uno de los ejes de la PRL en España, habría que preguntarse si existe un verdadero interés por parte de los poderes públicos en que esta materia se trate como se merece no ya en los niveles universitarios, sino también en los niveles inferiores de la enseñanza. Sólo así se creará una verdadera y deseable cultura preventiva en la sociedad y ésta podrá revertir de forma natural a la ciudadanía.

Esta reversión no sólo se producirá cuando se el ciudadano se incorpore al mundo laboral, sino también si éste llega a ejercer responsabilidades políticas legislando y reglamentando soluciones que remuevan obstáculos y planteando estrategias que actúen desde cada uno de los ámbitos que conforman la PRL, y que protejan verdaderamente el derecho del trabajador a ejercer su jornada laboral en las mejores condiciones de seguridad y salud, desarrollando una mejor tutela jurídica para los técnicos responsables en seguridad y salud laborales, que día tras día se enfrentan a la dura tarea de proponer las mejores soluciones para que esto sea así. Esta reversión también se producirá si el ciudadano opta por integrarse como responsable en el ámbito académico y educativo programando e impartiendo contenidos formativos más adecuados, cercanos $\mathrm{y}$

\footnotetext{
${ }^{18}$ En este sentido la exposición de motivos del Real Decreto 780/1998, de 30 de abril, por el que se modifica el Real Decreto 39/1997, de 17 de enero, por el que se aprueba el Reglamento de los servicios de prevención (BOE $\mathrm{n}^{\circ}$ 104, de 1 de mayo de 1998).señala en su tercer párrafo: «... Ante la inexistencia actual de titulaciones académicas o profesionales correspondientes a los niveles formativos mencionados, salvo en lo relativo a la especialidad de Medicina del Trabajo, se contempla la posibilidad transitoria de acreditación alternativa de la formación exigida, hasta tanto se determinen las titulaciones correspondientes por las autoridades competentes en materia educativa».

${ }^{19}$ El Informe Durán debe su nombre a Federico Durán López, Presidente del Consejo Económico y Social, el cual fue entregado el 13 de marzo de 2001 al Presidente del Gobierno. Dicho informe contenía un estudio sobre el estado por esas fechas de la siniestralidad en España.
} 
consonantes con la realidad laboral. O si se opta por el ámbito jurídico garantizando el cumplimiento del derecho al trabajo en unas condiciones de seguridad y salud óptimas, y la tutela efectiva y decidida del técnico en prevención que le permita el desarrollo de altas responsabilidades de forma autónoma, objetiva, íntegra y ética, frente a cualquier injerencia de terceros, especialmente con capacidad de influencia por su jerarquía.

Por último, esta reversión también se manifestará en la incorporación del ciudadano como responsable jerárquico, directivo o mando intermedio, en una organización empresarial, pública o privada, comprometiéndose con la política preventiva de ésta y difundiéndola a todos sus trabajadores, favoreciendo una cultura preventiva proactiva, situando a la prevención como un valor en si mismo más allá de parámetros productivos y económicos. En este escenario de colaboración entre todos los niveles jerárquicos, el trabajo del técnico de prevención se percibirá inadvertido, pudiendo éste centrar sus esfuerzos en otros aspectos y escenarios más desfavorables a los que apenas puede atender en culturas preventivas menos favorables, como es comprobar que las mejoras preventivas que propone se implementan y consiguen una reducción de la siniestralidad laboral a unos niveles mínimos. En definitiva, que la prevención se convierte en una herramienta efectiva y eficaz y no en un mero formalismo.

Aunque la figura central de nuestro estudio es el TSPRL, el hecho de que las funciones de nivel superior en materia de PRL incluya a las de nivel intermedio, además de que ambos tipos de profesionales coexistan y colaboren entre sí en el mismo entorno laboral, hace difícil abordar el estudio del profesional de nivel superior sin hacer referencia al de nivel intermedio, especialmente al tratar los requisitos formativos de acceso, que han mantenido en muchos aspectos una evolución normativa paralela.

\subsection{Niveles formativos y especialidades preventivas necesarios.}

La Directiva 89/391/CEE ${ }^{20}$ indica en su art. 7.8 que los Estados miembros definirán las capacidades, aptitudes necesarias y el número suficiente de los trabajadores designados y los técnicos prevencionistas que intervienen en la gestión de una empresa. La LPRL señala en su art. 31.4, que «el servicio de prevención tendrá carácter interdisciplinario, debiendo sus medios ser apropiados para cumplir sus funciones. Para ello, la formación, especialidad, capacitación y número de componentes de estos servicios, así como sus recursos técnicos, deberán ser suficientes y adecuados a las actividades preventivas a desarrollar». El art. 10 del RSP, recoge entre las posibles modalidades de la actividad preventiva en una empresa la asunción personal por el empresario, la designación de uno o varios trabajadores, la constitución de un servicio de prevención propio y el recurrir a un servicio de prevención ajeno.

Será en los citados servicios de prevención tanto propios como ajenos, incluyendo la opción de mancomunados, donde el TSPRL desempeñará sus funciones, no existiendo la posibilidad de ejercer éstas fuera de estas modalidades como autónomo o profesional liberal. Esta última posibilidad si bien existía en la Directiva 89/391/CEE desaparecerá y se interpretará de manera restrictiva al transponerse ésta al derecho español a través de la LPRL. Esta directiva recoge dicha posibilidad al contemplar en su art. 7.3 que «si las competencias en la empresa y/o establecimiento son insuficientes para organizar dichas actividades de protección y de prevención, el empresario deberá recurrir a competencias (personas o servicios) ajenas a la empresa y/o al establecimiento». Sin embargo, en su

\footnotetext{
${ }^{20}$ Directiva del Consejo 89/391/CEE, de 12 de junio de 1989, relativa a la aplicación de medidas para promover la mejora de la seguridad y de la salud de los trabajadores en el trabajo, publicada en DO ${ }^{0} \mathrm{~L}$ 183, de 29 de junio de 1989. Es conocida como Directiva Marco.
} 
transposición a la LPRL, ésta señala en su art. 30.1 que el empresario "constituirá un servicio de prevención o concertará dicho servicio con una entidad especializada ajena a la empresa» admitiéndose, en su art. 31.1, la posibilidad incluso de recurrirse a uno o varios servicios de prevención ajenos, señalándose esta posibilidad también en el art. 20.1 del RSP. Como vemos en estos artículos, se prescinde literalmente de la opción de acudir a una persona ajena a la empresa para las actividades preventivas.

Esta literalidad en la LPRL no está tan clara sin embargo, cuando esta actividad preventiva se refiere a la formación en materia preventiva de los trabajadores. Así, dicha ley, en su art. 19.2 señala que esta formación podrá impartirse por la empresa «mediante medios propios o concertándola con servicios ajenos...». La utilización del término «servicios ajenos» en vez de «servicios de prevención ajenos», entendemos que permite una interpretación según la cual si que podrían tener cabida las personas ajenas a la empresa en la realización de actividades preventivas como la formación, no siendo en este caso exclusiva su realización por entidades concertadas. Sin embargo esta posible interpretación de la LPRL será negada por la Subdirección General de Ordenación Normativa al señalar restrictivamente, en su escrito de 7 de febrero de $2014^{21}$, que la «única posibilidad de que la formación del art. 19 LPRL pueda llevarse a cabo por alguien externo a la empresa es que la imparta un servicio de prevención ajeno debidamente acreditado» y que por tanto, como «servicio ajeno» ha de entenderse en todo caso «servicio de prevención ajeno».

El RSP establece un número mínimo de las especialidades con las que contarán los servicios de prevención en cualquiera de sus modalidades. Para la modalidad de servicio propio, el art. 15 del RSP establece un mínimo de dos especialidades o disciplinas preventivas de las previstas en su art. 34, es decir, a elegir entre las cuatro siguientes: medicina en el trabajo, seguridad en el trabajo, higiene industrial, y ergonomía y psicosociología aplicada; éstas serán desarrolladas por expertos con la capacitación requerida para las funciones a desempeñar, que actuarán de forma coordinada. Además de estos técnicos el servicio de prevención propio contará con el personal necesario que tenga la capacitación requerida para desarrollar las funciones de los niveles básico e intermedio. No se dice nada en relación a que estas especialidades no puedan concurrir en un único técnico, ya que el RSP sólo señala al respecto (en su art. 15.2) que «los servicios de prevención propios deberán contar con las instalaciones y los medios humanos y materiales necesarios para la realización de las actividades preventivas que vayan a desarrollar en la empresa».

En el caso de un servicio de prevención ajeno, el RSP señala en su art. 18.2 que, en todo caso, estas entidades deberán... «contar con las especialidades o disciplinas preventivas de medicina del trabajo, seguridad en el trabajo, higiene industrial, y ergonomía aplicada». Es decir, deberán contar con las cuatro especialidades. En este caso, a diferencia del servicio propio, se contará con un número mínimo de técnicos por cada especialidad, al señalarse en este mismo artículo, que se dispondrá «como mínimo de un

21 Respuesta de la Subdirección General de Ordenación Normativa (Dirección General de Empleo del Ministerio de Empleo y Seguridad Social) sobre una consulta realizada por AEPSAL (Asociación de Especialistas en Prevención y Salud Laboral), sobre la posibilidad de que la formación preventiva de los trabajadores pueda ser realizada por personas ajenas en el caso de que no pueda serlo por medios propios, en referencia al art. 19 de la LPRL. [En línea] https://www.aepsal.com/wp-content/uploads/2015/02/ RespuestaSdGON-AEPSAL.pdf).

Tras esta respuesta, AEPSAL interpuso una denuncia ante la Comisión Europea por entender errónea la transposición del art. 7.3 de la Directiva 89/391/CEE en la aplicación actual de la legislación española. Véase dicha denuncia en https:/www.aepsal.com/wp-content/uploads/2015/02/DenunciaCE.pdf). 
técnico que cuente con la cualificación necesaria para el desempeño de las funciones de nivel superior, ... por cada una de las especialidades o disciplinas preventivas señaladas... salvo en el caso de la especialidad de medicina del trabajo que exigirá contar, al menos, con un médico especialista en medicina del trabajo o diplomado en medicina de empresa y un ATS/DUE de empresa. Además, será necesario disponer de personal con la capacitación requerida para desarrollar funciones de nivel básico e intermedio, en función de las características de las empresas cubiertas por el servicio de prevención ajeno. El art. 19.2 abre la posibilidad al servicio de prevención ajeno de subcontratar los servicios de otros profesionales o entidades cuando sea necesario para la realización de actividades que requieran conocimientos o instalaciones de gran complejidad.

En cuanto a los servicios de prevención mancomunados para los casos previstos en el art. 21 del RSP, aunque éstos suponen un caso especial de servicio de prevención propio compartido por varias empresas, se señala que éstos «habrán de contar con, al menos, tres especialidades o disciplinas preventivas». Además deberán de disponer de los recursos humanos mínimos equivalentes a los exigidos para los servicios de prevención ajenos. Por tanto, el número de especialidades necesarias será de un mínimo de dos en los servicios de prevención propios, un mínimo de tres en los servicios de prevención mancomunados y cuatro en los servicios de prevención ajenos.

\subsection{Funciones de los técnicos en prevención de riesgos laborales.}

Se ha señalado la exigencia de técnicos integrados en los servicios de prevención con diferentes funciones en materia de seguridad y salud laboral. En este epígrafe haremos referencia a esas funciones para comprender la capacitación que se les exige. Aunque nuestro estudio se centra especialmente en el técnico que realiza funciones preventivas de nivel superior, también señalaremos las funciones del técnico de nivel intermedio, que puede actuar de apoyo de aquél como veremos a continuación.

Las funciones correspondientes al nivel intermedio, contenidas en el art. 36.1 del RSP, incluyen la promoción e integración de la prevención en la empresa, la realización de evaluaciones de riesgos simples junto a la propuesta de medidas de control de éstos (siempre que no suponga la necesidad de especialización en algunas de las disciplinas de nivel superior), la información y formación básica de trabajadores, el seguimiento de dichas medidas de control, la participación en la planificación de la actividad preventiva y la dirección en las actuaciones a desarrollar en caso de emergencia y primeros auxilios, así como la colaboración con los servicios de prevención. Se contempla además la posibilidad de que se le asigne otras funciones auxiliares, complementarias o de colaboración con los técnicos del nivel superior.

Como se observa, las funciones del nivel intermedio no profundizan en ninguna de las disciplinas preventivas objeto de especialización de los técnicos del nivel superior, a los que como hemos indicado pueden servir de apoyo. A su vez, las funciones de nivel intermedio se encuentran incluidas y solapadas por las funciones de nivel superior. Éstas últimas se contienen en el art. 37.1 del RSP, entre las que se incluye además de las funciones de nivel intermedio, la realización de evaluaciones de riesgos y la planificación de la acción preventiva cuando por su complejidad sea necesaria una formación preventiva especializada, la formación e información a todos los niveles y en todas las materias. También se incluyen en este nivel las funciones de vigilancia y control de la salud laboral, en las cuales el personal sanitario especializado en medicina del trabajo tiene una especial relevancia. 


\subsection{Evolución de los requisitos formativos de acceso para los técnicos en prevención de riesgos laborales.}

Una vez señaladas las funciones del técnico en prevención de riesgos laborales, especialmente las referidas al que desarrolla funciones de nivel superior, y conocidas las cuatro especialidades preventivas, podremos establecer los contenidos formativos para acceder a dichas funciones. Hay que decir que los requisitos formativos para poder desempeñar las funciones en materia de seguridad y salud laborales han ido evolucionando desde sus orígenes, a pesar de lo cual la regulación en esta materia desde el enfoque verdaderamente preventivo es relativamente reciente en España, con la aprobación de la LPRL en el año 1995. Por ello, nos centraremos en la regulación existente desde que se aprueba esta ley hasta la actualidad.

Anteriormente a la LPRL y al RSP ya existían profesionales técnicos desempeñando funciones preventivas, formando parte de los servicios de seguridad e higiene en el trabajo y de los servicios médicos de empresa ${ }^{22}$. El RSP estableció en su Disposición Adicional Quinta la posibilidad de convalidar las funciones que venían desempeñando estos profesionales para adaptarlas al marco normativo actual. Dicho reglamento establecía originalmente en su Disposición Transitoria Tercera un periodo transitorio en relación a las titulaciones académicas y profesionales correspondientes a la formación mínima exigida relativa a las funciones de los niveles intermedio y superior en PRL, disposición que estuvo vigente hasta su derogación por el Real Decreto 337/201023. La existencia de diferentes marcos regulatorios de acceso a la profesión preventiva ha supuesto que, en la actualidad, coexistan técnicos que realizando sus funciones, bien sean de nivel intermedio o de nivel superior, han accedido a éstas con unos requisitos formativos muy diferentes según en qué período temporal ingresaron en este mercado laboral. A continuación señalaremos cómo han evolucionado esos requisitos desde la aprobación de la LPRL hasta la actualidad.

\section{3.a) Requisitos formativos de acceso a fecha de publicación de la LPRL al amparo del Apartado 1 de la Disposición Adicional Quinta del RSP.}

\footnotetext{
22 El RSP, en su disposición adicional segunda, integra el personal perteneciente a los servicios médicos de empresa, en la fecha de su entrada en vigor, en los servicios de prevención de las correspondientes empresas cuando éstos se constituyan, sin perjuicio de poder seguir desarrollando las funciones que tuvieran atribuidas distintas de las propias del servicio de prevención.

En cuanto a la actividad sanitaria de los servicios médicos, la aplicación del RSP, según su disposición adicional tercera, no afectará a la continuación de dicha actividad que se haya venido desarrollando en las empresas al amparo de las normas reguladoras de estos servicios que se derogan y de sus disposiciones de aplicación y desarrollo, aun cuando dichas empresas no constituyan servicios de prevención. Algo similar indica esta disposición adicional tercera para los servicios de seguridad e higiene en el trabajo existentes en las empresas a fecha de entrada del RSP, a cuyo mantenimiento este reglamento tampoco afectará aun cuando no concurran las circunstancias previstas en su art. 14 sobre los servicios de prevención propios. El Decreto 1036/1959, de 10 de junio de reorganización de los servicios médicos de empresa (BOE $n^{\circ} 148$, de 22 de junio de 1959) y la Orden de 21 de noviembre de 1959 por la que se aprueba el Reglamento de los servicios médicos de empresa (BOE $\mathrm{n}^{\circ} 284$, de 27 de noviembre de 1959) regulaban éstos servicios hasta la entrada en vigor del RSP, que deroga ambas normas.

${ }^{23}$ Real Decreto 337/2010, de 19 de marzo, por el que se modifican el Real Decreto 39/1997, de 17 de enero, por el que se aprueba el Reglamento de los Servicios de Prevención; el Real Decreto 1109/2007, de 24 de agosto, por el que se desarrolla la Ley 32/2006, de 18 de octubre, reguladora de la subcontratación en el sector de la construcción y el Real Decreto 1627/1997, de 24 de octubre, por el que se establecen disposiciones mínimas de seguridad y salud en obras de construcción. (BOE $\mathrm{n}^{\mathrm{o}}$ 71, de 23 de marzo de 2010).
} 
Este epígrafe hace referencia a los criterios de acceso para el ejercicio de las funciones de nivel intermedio y superior, indicada en los arts. 36 y 37 del RSP, a fecha de la publicación de la LPRL, el 10 de noviembre de 1995, al amparo del Apartado 1 de la Disposición Adicional Quinta del RSP.

Quienes a esta fecha vinieran realizando funciones de nivel intermedio o superior y no contaran con la formación mínima prevista en éstos, podrán continuar desempeñando dichas funciones en la empresa o entidad en que la vinieran desarrollando, siempre que cumplieran una serie de requisitos, en los que se incluía tener una experiencia no inferior a 3 años a partir de 1985 en funciones de nivel intermedio, y de 1 o 5 años en las de nivel superior en función de si se dispone o no de titulación universitaria. Además será necesario acreditar una formación preventiva específica no inferior a 100 horas cursada en algún organismo público o privado de reconocido prestigio (formación que no se será de aplicación al personal sanitario, que se rige por su normativa específica).

Es decir, los técnicos de nivel superior contemplados en este epígrafe sólo podrán seguir desarrollando sus funciones en la misma empresa o entidad en la que ya vinieran haciéndolo antes de la publicación de la LPRL, ya que carecen de la formación mínima exigida para los niveles intermedio o superior. No obstante, a partir de 1998 podrán ampliar sus funciones a otras empresas si cumplen los requisitos que se contienen en el epígrafe siguiente.

\section{3.b) Requisitos formativos de acceso durante el año 1998 al amparo del Apartado 2 de la Disposición Adicional Quinta del RSP.}

Los arts. 36.2 y 37.2 del RSP, que regulan los requisitos formativos mínimos para los niveles intermedio y superior, respectivamente, entrarían en vigor después del resto de disposiciones de dicho Reglamento. En la redacción original del RSP estaba previsto que lo hicieran a los 12 meses de su publicación, es decir, el 31 de enero de 1998, junto con el art. 35.2 (que hace referencia a los requisitos formativos mínimos para el nivel básico). Sin embargo, el Real Decreto 780/1998, al modificar el RSP, ampliará este plazo de entrada en vigor hasta el 31 de diciembre de 1998. Otra modificación realizada por este Real Decreto fue añadir un segundo apartado a la Disposición Adicional Quinta del RSP (al que hace referencia este epígrafe).

Los motivos de estas dos modificaciones del RSP se explican en la exposición de motivos del propio Real Decreto 780/1998. Uno de estos motivos guarda relación con el dictado de la Orden de 27 de junio de $1997^{24}$. Este hecho implica que el tiempo transcurrido entre la publicación del RSP el 31 de enero de 1997 y la entrada en vigor de esta Orden el 5 de julio de 1997 acorte el tiempo disponible para realizarse los proyectos formativos por parte de las entidades públicas o privadas interesadas en el desarrollo y certificación de actividades formativas en materia de PRL, una vez autorizadas por las autoridades laborales competentes, estando la mayoría de dichas entidades en pleno

\footnotetext{
24 Orden de 27 de junio de 1997 por la que se desarrolla el Real Decreto 39/1997, de 17 de enero, por el que se aprueba el Reglamento de los Servicios de Prevención, en relación con las condiciones de acreditación de las entidades especializadas como servicios de prevención ajenos a las empresas, de autorización de las personas o entidades especializadas que pretendan desarrollar la actividad de auditoría del sistema de prevención de las empresas y de autorización de las entidades públicas o privadas para desarrollar y certificar actividades formativas en materia de PRL. (BOE $\mathrm{n}^{\circ} 159$, de 4 de julio de 1997). (Derogada por la Orden TIN/2504/2010, de 20 de septiembre, por la que se desarrolla el Real Decreto 39/1997, de 17 de enero, por el que se aprueba el Reglamento de los Servicios de Prevención, en lo referido a la acreditación de entidades especializadas como servicios de prevención, memoria de actividades preventivas y autorización para realizar la actividad del sistema de prevención de las empresas. (BOE $\mathrm{n}^{\circ} 235$, de 28 de septiembre de 2010)).
} 
período de impartición de la formación. Esto supone que no se cuenten con suficientes profesionales que tengan certificada su formación mínima necesaria para poder ejercer las funciones de nivel intermedio o superior correspondientes a los arts. 36 y 37 del RSP. De hecho, en ambos niveles se comprueba que la aparición en el mercado de trabajo de técnicos con la acreditación requerida no cubre de manera apreciable la demanda existente en el momento de cumplirse el plazo inicialmente previsto para la entrada en vigor de los arts. 36.2 y 37.2. Otro de los motivos de las citadas modificaciones hace referencia a la constatación de la existencia de profesionales en los ámbitos de la actividad pública y privada que cuentan con un nivel de conocimientos y experiencia en el ejercicio de sus funciones de PRL equivalente, que han adquirido en el ejercicio de su profesión incluyendo la labor docente, pero que sin embargo, tienen dificultades al demostrar dichos conocimientos. Para ello, el Real Decreto 789/1998, añade en la Disposición Adicional Quinta del RSP la posibilidad de reconocer a tales profesionales mediante su certificación por la autoridad laboral que les habilite para el ejercicio de las funciones preventivas de nivel intermedio y superior. Por tanto, tras las modificaciones señaladas en la citada Disposición Adicional Quinta del RSP, señalamos a continuación cuáles son los requisitos que tendrán que cumplir los profesionales en esta segunda etapa descrita en este epígrafe 2.3.b) para desempeñar las funciones de los niveles intermedio y superior en materia de PRL. Como se observará, dichos requisitos se endurecen respecto a los del epígrafe 2.3.a).

Aquellos profesionales, descritos en el epígrafe 2.3.a), que durante el año 1998 vinieran desempeñando las funciones de nivel intermedio o nivel superior según los arts. 36 o 37 del RSP respectivamente, podrán ser acreditados por la autoridad laboral competente del lugar donde residiera el solicitante, expidiéndoles la correspondiente certificación de formación equivalente ${ }^{25}$ que les facultará para poder desempeñar las funciones correspondientes a dicha formación, tras la verificación del cumplimiento de una serie de requisitos, en los que se incluye una experiencia no inferior a 3 años a partir de 1985 en funciones de nivel intermedio o de nivel superior y la acreditación de poseer una formación específica en materia preventiva no inferior a 100 horas cursada en algún organismo público o privado de reconocido prestigio (que incluya los contenidos

\footnotetext{
${ }^{25}$ La expedición de esta certificación por la autoridad laboral competente se realizará de acuerdo al apartado 3 de la Disposición Adicional Quinta del RSP:

a) Mediante la valoración de la documentación acreditativa de la titulación poseída y de la correspondiente a los programas formativos de aquellos cursos recibidos que, dentro de los límites señalados en el apartado 2 de esta disposición deberá incluir los contenidos sustanciales de los anexos V o VI del RSP, según el caso. Se hará constar por el solicitante que esta formación ha sido superada con suficiencia en entidades formativas con una solvencia y prestigio reconocidos en su ámbito.

b) Mediante la valoración y la certificación de la experiencia acreditada por entidades o empresas donde se haya prestado los servicios. Esta experiencia deberá ser acorde con las funciones propias de cada nivel y, además con la especialidad preventiva a acreditar en el caso del nivel superior, incluyendo los cursos impartidos en su caso.

c) Mediante la verificación de estar en posesión de los conocimientos necesarios relativos a los aspectos no suficientemente demostrados en los apartados a) y b) que completen lo exigido en los anexos $\mathrm{V}$ o VI del RSP, mediante la superación de pruebas técnico-prácticas que determinen las capacidades y aptitudes exigidas para el desarrollo de las funciones de nivel intermedio y superior, respectivamente.
} 
sustanciales de los anexos $\mathrm{V}^{26} \mathrm{o} \mathrm{VI}^{27}$ del RSP según el caso). Además será necesario poseer una titulación universitaria de primer o segundo ciclo si se solicita la acreditación para el nivel superior. Durante el año 1998, también podrán acceder a esta acreditación aquellos profesionales que, en virtud de los conocimientos adquiridos y de su experiencia profesional anterior a la publicación de la LPRL, debidamente acreditados, contarán con la cualificación necesaria para desempeñar las funciones de nivel intermedio o nivel superior en alguna de las tres especialidades de seguridad en el trabajo, higiene industrial y ergonomía y psicosociología aplicada. Antes de acceder a esta acreditación tendrá que cumplir con los tres requisitos señalados en este epígrafe.

\section{3.c) Requisitos formativos de acceso al amparo de la Disposición Transitoria Tercera del RSP antes de la entrada en vigor del Real Decreto 337/2010.}

Este período temporal de estudio de los requisitos de acceso a las funciones de nivel intermedio y superior en materia de PRL se sitúa al amparo de la Disposición Transitoria Tercera del RSP, y finaliza con la entrada en vigor del Real Decreto 337/2010 28 , el 24 de marzo de 2010.

Ante la inexistencia, a fecha de la entrada en vigor del RSP, de titulaciones académicas o profesionales correspondientes a los niveles formativos intermedio y superior en materia de PRL, el RSP establecía en su Disposición Transitoria Tercera ${ }^{29}$, un período transitorio de acreditación alternativa de la formación exigida, hasta tanto se determinaran las titulaciones correspondientes por las autoridades competentes en materia de educación. En este sentido, se señalaba en dicha disposición transitoria que, en tanto no se determinaran por las autoridades educativas las titulaciones académicas y profesionales correspondientes a la formación mínima exigida para el nivel intermedio y superior en los arts. 36 y 37 del RSP respectivamente, dicha formación podría ser acreditada sin efectos académicos a través de certificación expedida por una entidad

\footnotetext{
${ }^{26}$ El Anexo V del RSP trata del «Contenido mínimo del programa de formación, para el desempeño de las funciones de nivel intermedio». Contiene los siguientes bloques temáticos con la distribución de carga lectiva horaria indicada:

I. Conceptos básicos sobre seguridad y salud en el trabajo, $20 \mathrm{~h}$.

II. Metodología de la prevención I: Técnicas generales de análisis, evaluación y control de los riesgos. $170 \mathrm{~h}$.

III. Metodología de la prevención II: Técnicas específicas de seguimiento y control de los riesgos. 40h.

IV. Metodología de la prevención III: Promoción de la prevención. $20 \mathrm{~h}$.

V. Organización y gestión de la prevención. 50h.

${ }^{27}$ El Anexo VI del RSP trata del «Contenido mínimo del programa de formación, para el desempeño de las funciones de nivel superior». Este programa consta de tres partes, con una distribución de la carga lectiva horaria indicada:

I. Obligatoria y común (mínimo 350h), con los siguientes contenidos: 1. Fundamentos de las técnicas de mejora de las condiciones de trabajo, 20h. 2. Técnicas de prevención de riesgos laborales, 200h. 3. Otras actuaciones en materia de prevención de riesgos laborales, 30h. 4. Gestión de la prevención de riesgos laborales, 40h. 5. Técnicas afines, 20h. 6. Ámbito jurídico de la prevención, 40h.

II. Especialización optativa, a elegir entre las siguientes opciones: A) Seguridad en el trabajo, B) Higiene industrial, C) Ergonomía y psicosociología aplicada. Cada opción con un mínimo de 100h.

III. Realización de un trabajo final o de actividades preventivas en un centro de trabajo acorde con la especialización optada, mínimo $150 \mathrm{~h}$.

28 Real Decreto 337/2010, de 19 de marzo, por el que se modifican el Real Decreto 39/1997, de 17 de enero por el que se aprueba el Reglamento de los Servicios de Prevención; el Real Decreto 1109/2007, de 24 de agosto, por el que se desarrolla la Ley 32/2006, de 18 de octubre, reguladora de la subcontratación en el sector de la construcción y el Real Decreto 1627/1997, de 24 de octubre, por el que se establecen disposiciones mínimas de seguridad y salud en obras de construcción. ( $\mathrm{BOE} \mathrm{n}^{\mathrm{o}}$ 71, de 23 de marzo de 2010).

${ }^{29}$ Esta disposición fue derogada por el Real Decreto 337/2010.
} 
pública o privada que tuviera capacidad para desarrollar actividades formativas en esta materia y estuviera autorizada por la autoridad laboral competente. La Orden de 27 de junio de $1997^{30}$ señalaba en su art. 7 cuáles eran los requisitos mínimos que tenían que cumplir dichas entidades formativas para ser autorizadas para desarrollar y certificar actividades formativas en materia de PRL.

La citada Orden contemplaba entre los requisitos mínimos exigidos: la disposición de instalaciones y medios materiales y didácticos adecuados; el establecimiento de un programa formativo acorde a los contenidos de su art. 8.2 a) ${ }^{31}$; la disposición de acceso a biblioteca y bases bibliográficas; y una dotación de personal docente experto en las materias de las disciplinas a impartir que contara con una experiencia profesional de 3 años en dichas materias, que en el caso de corresponder a formación para desarrollar funciones de nivel superior sería de 5 años además de deber disponer de una titulación universitaria. En el caso de que se previera la realización de actividades preventivas en un centro de trabajo, la entidad formativa tenía que disponer de un concierto con empresas o entidades. Además, se podían concertar acuerdos entre varias de estas entidades formativas para una mejor dotación de personal docente.

Dicha Orden señalaba en su art. 10 cuál debía ser el alcance de la autorización para certificar las actividades formativas, indicando que ésta solo podía referirse a la certificación de actividades desarrolladas totalmente por la propia entidad y a la certificación por actividades desarrolladas parcialmente por la entidad. Esta autorización debía contemplar expresamente, en su caso, la posibilidad de que la entidad formativa pretendiera certificar enseñanzas impartidas por ella misma antes de la autorización. Dicha certificación se expediría previa comprobación de que se había cursado un programa con el contenido señalado en los anexos V o VI del RSP, y de la superación de una prueba de evaluación sobre dicho programa, o de que se contaba con una formación equivalente que hubiera sido legalmente exigida para ejercer una actividad profesional. En el caso de formación para desarrollar funciones del nivel superior, además sería requisito indispensable que el alumno poseyera una titulación universitaria.

Por tanto, en este epígrafe 2.3.c) queda patente la existencia de una tercera vía de acceso a los requisitos formativos para los profesionales que desempeñen sus funciones de nivel intermedio o superior, considerando las dos vías estudiadas en los anteriores epígrafes 2.3.a) y 2.3.b) de este trabajo. De este modo, la Disposición Adicional Primera del Real Decreto 337/2010 señala que los técnicos cuya formación en materia de PRL hubiera sido acreditada sin efectos académicos mediante la certificación descrita en este epígrafe al amparo de la Disposición Transitoria Tercera del RSP, obtenida antes de la entrada en vigor de este Real Decreto, el 24 de marzo de 2010, podrán seguir desempeñando las funciones de nivel intermedio o superior, referidas respectivamente en

\footnotetext{
30 Véase el epígrafe 5.2 de este trabajo.

${ }^{31}$ Un programa formativo anual o plurianual establecido de acuerdo a los criterios del Anexo III y los contenidos de los anexos Vo VI del RSP, en particular lo siguiente:

1. Objetivos generales y específicos.

2. Programa de formación. Contenidos. Duración. Calendario.

3. Metodología. Actividades didácticas.

4. Modalidades de evaluación previstas para constatar el aprovechamiento de la formación impartida.

5. En el caso de que se vayan a realizar actividades preventivas en un centro de trabajo, concreción de las mismas, así como de los centros de trabajo previstos.

6. Sistema de evaluación interna de la calidad de la docencia impartida.
}

El Anexo III del RSP hace referencia a los «Criterios generales para el establecimiento de proyectos y programas formativos, para el desempeño de las funciones de nivel básico, medio y superior». 
los arts. 36 y 37 del RSP. De la lectura de la Disposición Adicional Primera del Real Decreto 337/2010, también podemos considerar incluidos en esta tercera vía de acceso a aquellos técnicos cuya formación en la fecha de publicación de este Real Decreto, el 23 de marzo de 2010, estuviese en curso de ser acreditada sin efectos académicos mediante la certificación referida anteriormente, permitiéndoles, una vez obtenida la misma, tener plena capacidad para desempeñar las funciones de nivel intermedio o superior.

Además, de la formación de acceso descrita hasta ahora en este epígrafe impartida por entidades formativas autorizadas por la autoridad laboral, a partir del curso 20062007 las universidades españolas podrán ofertar másteres relacionados con la PRL ${ }^{32}$, coexistiendo durante algún tiempo ambas vías formativas. Será con la modificación del art. 37.2 del RSP cuando sólo quede disponible la vía universitaria para acceder a esta formación, como veremos en el siguiente epígrafe de este trabajo.

Dentro del intervalo temporal marcado por este epígrafe, citaremos tres hitos por su influencia en el modelo de la PRL en España, y en especial, en el tratamiento de la integración de la formación y la educación en el modelo preventivo. Nos referimos al Informe Durán (2001), a la Estrategia Española de Seguridad y Salud en el Trabajo 20072012 y al Plan Nacional de Formación en Prevención de Riesgos Laborales (previsto realizar para 2009 e implantar a partir de 2010 como una de las medidas de dicha Estrategia. Estos hitos no pueden explicarse al margen de los marcos preventivos internacional (Convenios de la Organización Internacional del Trabajo) y europeo (estrategias comunitarias) adoptados hasta esas fechas.

\section{3.d) Requisitos formativos de acceso después de la entrada en vigor del Real} Decreto 337/2010, a partir del 24 de marzo de 2010.

Las modificaciones planteadas por el Real Decreto 337/2010 se basan en las propuestas de la EESST 2007-2012, en especial la señalada en su línea de actuación 6.3 que incide sobre el art. 37.2 del RSP, referido a la formación para las funciones de nivel superior. Este Real Decreto también se nutre de las cuestiones planteadas y debatidas dentro de un grupo de trabajo constituido por la Administración General del Estado y Comunidades Autónomas, y con las organizaciones sindicales y empresariales, que dará como resultado un documento de consenso sobre «las actuaciones para la mejora de la calidad y eficacia del sistema de prevención de riesgos laborales». Dicho Real Decreto deroga la Disposición Transitoria Tercera del RSP y con ello finaliza la etapa de transición hacia la acreditación formativa actual de los profesionales en materia de PRL. A partir de la entrada en vigor de este Real Decreto, la vía de acceso para los nuevos profesionales que quieran ejercer estas funciones será a través de una titulación académica y profesional, lo cual no impedirá mantener la validez de las acreditaciones realizadas al amparo de esta disposición transitoria y de otras anteriores a este Real Decreto, como hemos visto en los epígrafes anteriores de este trabajo.

En el caso de las funciones de nivel intermedio recogidas en el art. 36 del RSP, para desempeñar éstas, actualmente se exige cursar el título de formación profesional de Técnico Superior en Prevención de Riesgos Profesionales, cuya regulación se establece

\footnotetext{
32 Véase el apartado 7 del Plan Nacional de Formación en Prevención de Riesgos Laborales.
} 
en los Reales Decretos $1161 / 2001^{33}$ y $227 / 2003^{34}$, y que será actualizado de acuerdo a la Ley Orgánica 2/2006 de educación ${ }^{35}$. Este ciclo formativo se ha implantado en todas las Comunidades Autónomas y en las ciudades de Ceuta y Melilla, y a fecha de 13 de abril de 2013 existían 107 centros que impartían este ciclo, 90 públicos y 9 de carácter privado $^{36}$. Al contrario de, como veremos ocurre con la formación de nivel superior, los requisitos formativos para desempeñar las funciones de nivel intermedio no son modificados por el Real Decreto 337/2010 y se mantiene la redacción original del art. 36.2 del RSP que las regula, estableciendo los siguientes requisitos: poseer una formación mínima con el contenido del programa referido en el Anexo V del RSP, cuya desarrollo tendrá una duración no inferior a 300 horas y una distribución horaria adecuada a cada proyecto formativo, respetando la establecida en el anexo citado.

Sin embargo, el Real Decreto 337/2010 si modifica los requisitos de formación para el desempeño de las funciones de nivel superior, al modificar el art. 37.2 del RSP. Hasta antes de la entrada en vigor de este Real Decreto, cuando en las etapas contempladas en los epígrafes 2.3.a), 2.3.b) y 2.3.c) de este trabajo se mencionaban los requisitos formativos para desempeñar estas funciones y se remitía a este artículo, se hacía referencia al cumplimiento de los requisitos establecidos en la redacción original del RSP. Dichos requisitos exigían tener una titulación académica, además de poseer una formación mínima con el contenido especificado en el programa del Anexo VI del RSP con una duración no inferior a 600 horas y una distribución horaria adecuada a cada proyecto formativo, respetando la establecida en el citado anexo.

Como ya hemos señalado, la entrada del Real Decreto 337/2010 supone el fin de la transitoriedad en la formación de acceso para los profesionales de nivel superior en esta materia, no admitiéndose otra formación que la acreditada por una universidad, agotándose de este modo la previsión establecida en la Disposición Transitoria Tercera del RSP, según la cual, hasta que no se determinasen por las autoridades competentes educativas las titulaciones académicas y profesionales correspondientes a la formación mínima señalada en los arts. 36 y, en nuestro caso, 37 del RSP, «podrá» ser acreditada dicha formación sin efectos académicos con la correspondiente certificación expedida por una entidad pública o privada autorizada por la autoridad laboral competente. Se resalta entrecomillado «podrá» porque, en efecto, la citada disposición transitoria deja abiertas otras vías de acreditación más allá de la no académica. De hecho, ya antes de la entrada en vigor del Real Decreto 337/2010 existían titulaciones académicas universitarias en esta materia que habilitaban para el ejercicio de estas funciones, aunque su número era entonces despreciable en relación al del resto de ofertas formativas. Por tanto, la modificación operada por este Real Decreto sobre el art. 37.2 del RSP supone una restricción de los requisitos establecidos inicialmente en dicho artículo, al señalar su nueva redacción que la titulación universitaria ha de ser «oficial» y que la formación mínima poseída ha de ser «acreditada» por una universidad con el contenido especificado

\footnotetext{
${ }^{33}$ Real Decreto 1161/2001, de 26 de octubre, por el que se establece el título de Técnico Superior en Prevención de Riesgos Profesionales y las correspondientes enseñanzas mínimas. (BOE nº 279, de 21 de noviembre de 2001),

${ }^{34}$ Real Decreto 277/2003, de 7 de marzo, por el que se establece el currículo del ciclo formativo de grado superior correspondiente al título de Técnico Superior en Prevención de Riesgos Profesionales. (BOE ${ }^{\circ}$ 74, de 27 de marzo de 2003).

${ }^{35}$ Ley Orgánica 2/2006, de 3 de mayo, de educación. (BOE no 106, de 4 de mayo de 2006).

36 Vid. INSHT (2013). Balance final de la Estrategia Española de Seguridad y Salud en el Trabajo (20072012), p. 57.
} 
en el anexo VI. La modificación no afecta a los requisitos de contenido, duración y distribución horaria de esta formación mínima.

Esto supone que en la práctica esta formación de nivel superior se desarrolle de manera generalizada a través de una titulación universitaria de máster. A fecha de 31 de diciembre de 2012, en el Registro de Universidades, Centros y Títulos se reflejaban 60 másteres oficiales en PRL, de los cuales más de la mitad correspondían a universidades públicas y el resto a privadas, sujetos al control de la Agencia Nacional de la Calidad y Acreditación (ANECA) ${ }^{37}$. Según el art. 4 del Real Decreto 1027/2011 ${ }^{38}$, de 15 de julio, por el que se establece el Marco Español de Cualificaciones para la Educación Superior (MECES), el nivel de máster corresponde a uno de los cuatro niveles en los que se estructura dicho Marco ${ }^{39}$; concretamente, según su art. 7, estos estudios se constituyen en el nivel 3 «en el que se incluyen aquellas cualificaciones que tienen como finalidad la adquisición por el estudiante de una formación avanzada, de carácter especializado o multidisciplinar, orientada a la especialización académica o profesional, o bien a promover la iniciación en tareas investigadoras».

A pesar de la reforma del art. 37.2 del RSP por el Real Decreto 337/2010, y en la línea de lo que señala García Jiménez ${ }^{40}$, dicho reglamento presenta un nivel tal de indefinición que ha favorecido muchas de las inconsistencias actuales con las que cuenta la formación superior en PRL, partiendo de la no concreción de cuál ha de ser la formación que habilite para el ejercicio profesional de las funciones de este nivel, lo que conlleva a no quedar claro si dicha formación se puede realizar a través de un grado o de un máster universitario oficiales ${ }^{41}$, o también cabe la posibilidad, como de hecho ocurre en la práctica, de realizarse a través de cursos universitarios de especialización dentro del catálogo de títulos propios de la universidad, o incluso va más allá, con la posibilidad de ser realizada a través de entidades «acreditadas» o «concertadas» por una universidad.

Quizás en esta dirección iba la propuesta de modificación del art. 37.2 del RSP en el Plan Nacional de Formación para la Prevención de Riesgos Laborales. Esta propuesta finalmente no se llegó a plasmar en dicho reglamento perdiéndose una oportunidad de haber aclarado la ambigüedad, pretendida o no, de la norma en este aspecto, al poder haber restringido expresamente la formación universitaria basada en el Anexo VI a la de carácter oficial. Dicha propuesta señalaba:

Para desempeñar las funciones relacionadas en el apartado anterior será preciso estar en posesión de un título universitario oficial y acreditar la superación de una formación oficial impartida por una universidad de acuerdo con el programa formativo establecido en el Anexo VI, en relación, al menos, con una de las especializaciones indicadas en la parte II de dicho Anexo.

Dicho Plan de Formación además recomendará en su apartado 7 el establecimiento de criterios comunes para facilitar y orientar la traslación del programa formativo, en

\footnotetext{
${ }^{37}$ INSHT. Op. cit., p. 56.

38 Publicado en BOE n ${ }^{\circ} 185$, de 3 de agosto de 2011.

39 Nivel 1: Técnico Superior; Nivel 2: Grado; Nivel 3: Máster; Nivel 4: Doctor.

40 GARCÍA JIMÉNEZ. Op. cit., pp. 132-133.

41 Cuando hablamos de titulaciones universitarias oficiales nos referimos a aquellas que han sido previamente evaluadas favorablemente por la ANECA, verificadas por el Consejo de Universidades, autorizadas en su implantación por las correspondientes Comunidades Autónomas, - según el art. 35.2 de la Ley Orgánica 6/2001 de 12 de diciembre, de Universidades (BOE nº 307, de 24 de diciembre de 2001), modificada por la Ley Orgánica 4/2007 de 12 de abril (BOE nº 89, de 13 de abril de 2007)-, y haber sido inscritas en el Registro de Universidades, Centros y Títulos. Ibíd., p. 132.
} 
cuanto a contenidos y duraciones, establecido en el Anexo VI del RSP a los planes de estudios de los títulos que acrediten para el desempeño de las funciones de nivel superior, de acuerdo a lo que establece el art. 37.2 del RSP. Estos criterios comunes sugieren que las universidades han de establecer criterios preferentes de admisión a esta formación del Anexo VI, en función de la rama del conocimiento a la que esté adscrito el título oficial desde el que se acceda.

El Anexo III del RSP establece que la formación en PRL para el desempeño de las funciones de nivel básico, medio y superior «ha de ser integradora de las distintas disciplinas preventivas que doten a los programas de las características multidisciplinar e interdisciplinar». Señala que los proyectos formativos se diseñaran según los criterios y la singularidad de cada promotor, estableciendo los siguientes elementos: objetivos generales y específicos, contenidos, articulación de las materias, metodología, modalidades de evaluación, recomendaciones temporales y soportes y recursos técnicos. Los programas formativos, a propuesta de cada promotor, en base a los proyectos y diseño curriculares, recogerán una concreción temporalizada de los objetivos y contenidos, además de su desarrollo metodológico, las actividades didácticas y los criterios y parámetros de evaluación de los objetivos que se hubieran formulado en cada programa.

Es decir, se da a las universidades, en palabras de García Jiménez ${ }^{42}$, «una amplia capacidad de concretar y desarrollar el programa formativo [...] dejando de este modo, a decisiones puntuales -de política interna universitaria- y que no siempre responden a la búsqueda de la calidad formativa» lo que puede suponer, en palabras del autor ${ }^{43}$ "una definición del programa formativo que presenta importantes descompensaciones, en cuanto a carga lectiva y contenidos, sobre las materias» contempladas en el Anexo VI del RSP. Esta situación puede tener graves consecuencias sobre la capacitación del futuro profesional en PRL, al generarse una desconexión entre los títulos universitarios ofertados como másteres universitarios en PRL y las necesidades formativas que éstos pretenden cubrir para realizar las funciones de nivel superior del art. 37 del RSP. De hecho, otra consecuencia palpable del extremo al que puede llegar esta amplia capacidad de desarrollo del programa formativo del Anexo VI por parte de las universidades promotoras es la coexistencia en la oferta actual formativa de másteres universitarios que habilitan para estas funciones, con cargas lectivas muy dispares, que van desde los 60 créditos $\mathrm{ECTS}^{44}, 90$ créditos ECTS hasta los 120 créditos ECTS, con una duración temporal de 1 año, 1 año y medio y 2 años, respectivamente. Además, no todos estos másteres habilitan para las tres especialidades (seguridad en el trabajo, higiene industrial, ergonomía y psicosociología aplicada), sino que algunos sólo lo hacen para una de ellas, a cambio de incluir en sus programas contenidos de otras materias con cierto grado de afinidad con la PRL como son el medio ambiente, la gestión de la calidad o la integradora responsabilidad social corporativa. Con esta ampliación de materias se dota a estos estudios de postgrado de un contenido polivalente y flexible que los hace atractivos no sólo a aquellos futuros profesionales de la PRL, sino también a aquellos profesionales que ya ejercen en este sector pero que no cuentan con alguna de las tres especialidades

\footnotetext{
42 GARCÍA JIMÉNEZ. Op. cit., p. 133.

43 Ibid., p. 133.

${ }^{44}$ ECTS: Sistema Europeo de Transferencia de Créditos. El número mínimo de horas por crédito ECTS es de 25, y el número máximo de 30 (art. 4 del Real Decreto 1125/2003, de 5 de septiembre, por el que se establece el sistema europeo de créditos y el sistema de calificaciones en las titulaciones universitarias de carácter oficial y validez en todo el territorio nacional (BOE $\mathrm{n}^{\circ} 224$, de 19 de septiembre de 2003).
} 
señaladas, o simplemente, la de quienes prefieren ampliar su horizonte profesional con un currículum formativo más allá del mundo de la prevención.

Otro problema no resuelto es el acceso a esta formación con el formato de máster desde otras titulaciones universitarias no estando claramente establecidos cuáles son los contenidos formativos complementarios necesarios según la formación de procedencia. En este punto, habría que preguntarse por qué apenas se incluye, o cuando se hace por qué no siempre lo es con carácter obligatorio, la formación en materia preventiva en los programas formativos de aquellas titulaciones universitarias más afines a la PRL como pueden ser algunas ingenierías o arquitectura, por citar dos claros ejemplos, cuyos profesionales debieran contar con una formación inicial en esta materia por las funciones que realizan, las cuales incluyen el enfrentarse o gestionar situaciones donde la PRL adquiere un protagonismo importante por la gravedad de los riesgos presentes. Otro ejemplo de la falta de integración de la formación preventiva en los estudios universitarios es el carácter residual que presenta dicha formación dentro de los currículos formativos y planes de estudios de los grados universitarios, a pesar de las líneas de actuación que se han aprobado en los diferentes planes y estrategias en los últimos 20 años en España. Este hecho es un exponente de la pobre cultura preventiva y el muy mejorable compromiso a nivel institucional en la integración de la prevención en la educación y formación.

Como ejemplo ilustrativo de la aparición de contenidos en materia de PRL en los planes de estudios universitarios nos centraremos en los relativos a los Grados ofertados por la Universidad de Málaga en el curso académico 2019-2020 $0^{45}$ con una mayor afinidad con la PRL como son las ingenierías, arquitecturas y estudios de relaciones laborales, analizando las asignaturas cuya denominación esté directamente relacionada con la PRL. Así, en los planes de estudios de las Ingenierías encontramos la asignatura de «Seguridad y Salud Laboral» de carácter optativo en los Grados de Ingeniería Electrónica Industrial, Ingeniería Eléctrica, Ingeniería Mecánica, e Ingeniería en Diseño Industrial y Desarrollo del Producto. En el Grado en Ingeniería de Organización Industrial encontramos la asignatura de «Seguridad Laboral e Industrial» de carácter obligatorio y las asignaturas de «Gestión de la Prevención de Riesgos Laborales» y «Responsabilidad Social Corporativa y Sostenibilidad» de carácter optativo. No aparece ninguna asignatura con denominación directamente relacionada con la PRL en los Grados en Ingeniería Electrónica, Robótica y Mecatrónica, en Ingeniería de la Energía, ni en Ingeniería en Tecnologías Industriales. Tampoco aparece ninguna asignatura en los Grados en Arquitectura ni en Fundamentos de Arquitectura. No obstante, destaca favorablemente el Grado en Relaciones Laborales y Recursos Humanos, con la inclusión con carácter obligatorio de las asignaturas de «Salud Laboral» y de «Prevención de Riesgos Laborales». Estas asignaturas señaladas en los Grados anteriores suponen una formación académica para el alumno que le permitirá desempeñar las funciones como técnico de nivel básico en PRL del art. 35 del RSP. Pero no menos importante que los contenidos formativos necesarios para adquirir las capacidades y aptitudes para el desempeño de las funciones preventivas de los diferentes niveles (arts. 35, 36 y 37 RSP), lo es la metodología utilizada ${ }^{46}$ en su impartición, de la cual dependerá el grado de asimilación

\footnotetext{
45 Véanse en la web de la Universidad de Málaga http://www.uma.es. Respecto a los estudios relacionados con el ámbito sanitario como Medicina, Psicología o Enfermería, tampoco se ha observado en sus planes de estudios ninguna asignatura que trate la PRL de forma integral.

46 Véanse como ejemplos de una metodología innovadora en este aspecto la utilizada en la impartición de la asignatura de «Prevención de Riesgos Laborales» en el Grado en Relaciones Laborales y Recursos Humanos de la Universidad de Málaga (LÓPEZ INSUA, B.M. (2014). "La prevención de riesgos laborales a escena: un desafío para los nuevos sistemas de metodología docente”. En M. ABOUSSI (COORD.), M.T.
} 
de los contenidos por los alumnos, y con ello, el grado de asimilación en ellos de la cultura preventiva como futuros profesionales de la PRL o como futuros agentes participantes en su gestión.

Sin embargo, este fracaso en la integración de la educación y la formación en la PRL no sólo afecta a la formación de nivel superior en PRL, sino que también la encontramos en la formación preventiva de nivel intermedio, constatando las dificultades en la inserción laboral de los técnicos que desempeñan funciones de este nivel. La formación de estos técnicos cuenta con un tratamiento desigual tanto en duración de los estudios como en las oportunidades laborales, que hace necesario replantear un cambio normativo en cuyo diseño participen las instituciones involucradas y los agentes sociales. Para conocer cuál será el devenir de la educación y de la formación en materia preventiva en los próximos años en base a las oportunidades de mejora y soluciones propuestas por la política nacional en esta materia, y cuál es el verdadero compromiso institucional en implantarlas al objeto de consolidar la integración de la educación y formación en el sistema preventivo español, es conveniente remitirnos al contenido de la Estrategia Española de Seguridad y Salud en el Trabajo 2015-2020.

\section{Conclusiones.}

Los técnicos de PRL son la «punta de lanza» de la gestión preventiva en una organización y una manifestación palpable del grado de implantación en ella de la cultura de la prevención. En este sentido, la formación de estos profesionales adquiere un valor esencial en su capacitación para hacer frente a sus responsabilidades consistentes básicamente en gestionar la obligación del empresario que deriva del derecho de sus trabajadores a unas condiciones óptimas de seguridad y salud en su entorno de trabajo, es decir, se trata de garantizar el derecho al trabajo pero en armonía con el derecho fundamental a la vida, a la integridad física y moral. Derecho fundamental que explica el nivel de responsabilidad del técnico PRL. Pero esa responsabilidad exige de este profesional una capacitación suficiente y necesaria para llevar a cabo sus funciones. Para ello es vital una formación de acceso a a dicha funciones que luego será necesario completar con una formación permanente en su puesto de trabajo.

A pesar de haber transcurrido más de 20 años desde la aprobación de la LPRL, y de las políticas desarrolladas en España para su implantación real y efectiva, a día de hoy es cuestionable que éstas hayan tenido éxito en cuanto se refiere a la capacitación de los profesionales de la PRL en base a un diagnóstico de una formación de acceso que dista mucho de ser idónea, suficiente y efectiva para dar la mejor respuesta a los retos con los que estos profesionales se encuentran en su día a día. Las carencias de esta formación obedecen a múltiples causas pero destaca una dispersión de los programas de contenidos formativos en PRL impartidos por una excesiva variedad de entidades, con unas prioridades no siempre en consonancia con la esencia de la prevención y que demasiadas veces se rigen por criterios alejados de la motivación inicial de ésta, motivadas a su vez por una política formativa en PRL alejada de las necesidades reales. En este sentido, la consolidación de la formación y por extensión, de la educación en materia preventiva son vitales para conseguir un giro en el enfoque de la capacitación del profesional de la PRL,

DÍAZ AZNARTE LÓPEZ, M.I. GRANADOS ROMERA (DIRS.). Prácticas de innovación docente en ciencias sociales y jurídicas, pp. 143-148), y de la misma asignatura en el Doble Grado en Relaciones Laborales y Recursos Humanos y Finanzas y Contabilidad de la Universidad de Sevilla (DOMÍNGUEZ, ANA (2018). "Innovar en la asignatura de Prevención de Riesgos laborales ¿una cuestión de riesgos o de protección de la enseñanza?" Jornadas de Formación e Innovación Docente del Profesorado, 1, 198-215). 
como reiteran las diferentes estrategias en materia de seguridad y salud nacionales, comunitarias e internacionales. Para propiciar este cambio de enfoque es necesario incidir más allá del ámbito laboral, hay que actuar sobre la ciudadanía, en toda la extensión y niveles de la sociedad, para asimilar la cultura de la prevención en la conciencia colectiva.

A pesar de las políticas desarrolladas en formación y educación en PRL desde el inicio de la andadura de la LPRL, desde entonces no se han producido cambios sustanciales en las demandas de éstas, ni se ha terminado de conseguir la pretendida integración de la educación y formación en la mejora de la cultura preventiva. En este punto cabría preguntarse, si es la falta de esa cultura preventiva la que motiva este aparente desinterés y apatía institucional que se plasma en unas políticas que no llegan a consolidar esa integración, teniendo en cuenta que nuestros gestores públicos son integrantes, a su vez, de esa sociedad que adolece de una escasa cultura preventiva. En definitiva, podemos plantearnos si son unas políticas erróneas las causantes de una educación y formación en materia preventiva deficientes, o quizás habría que cambiar el sujeto en esta pregunta y reflexionar si son precisamente una educación y formación pobres en esta materia las que generan unas políticas erróneas al estar imbuidos sus máximos responsables, tanto los que la elaboran como los que la implantan, de una pobre cultura preventiva.

\section{Bibliografía.}

- AGUILERA IZQUIERDO, R. (2000). "Sobre las garantías de los trabajadores que ejercen funciones preventivas". Aranzadi Social (Estudios doctrinales), 3, 29942998.

- COBOS SANCHIZ, D. (2006). "La formación del técnico superior en prevención de riesgos laborales en España: estudio Delphi”. Prevention World Magazine, 14, 24-31.

- DOMÍNGUEZ, A. (2018). "Innovar en la asignatura de Prevención de Riesgos laborales ¿una cuestión de riesgos o de protección de la enseñanza?" Jornadas de Formación e Innovación Docente del Profesorado, 1, 198-215.

- GARCÍA JIMÉNEZ, M. (2016). "Luces y sombras de la formación en materia de prevención de riesgos laborales: Balance crítico y claves para una reforma". En MOLINA NAVARRETE, C.; GARCÍA JIMÉNEZ, M. y SORIANO SERRANO, M. (Dirs.). Ley de Prevención de Riesgos Laborales: Una revisión crítica, veinte años después. Madrid: Centro de Estudios Financieros, pp. 129-134.

- GARRIGUES GIMÉNEZ, A. (2005). "La prevención de riesgos laborales en el marco de la Constitución Europea". Revista del Ministerio de Trabajo e Inmigración, 57, 353366.

- GONZÁLEZ DÍAS, F.A. (2002). "Fuentes constitucionales y pilares normativos de la obligación de seguridad y salud en el trabajo". Aranzadi Social (Estudios doctrinales), 5, 705-740. 
- IGARTUA MIRÓ, M.T. (2014). "Los másteres universitarios «oficiales»: luces y sombras en su implantación y en el proceso de enseñanza-aprendizaje". En AA.VV.. Calidad de la docencia universitaria y encuestas: balance del Plan Bolonia, pp. 97136

- INSTITUTO NACIONAL DE SEGURIDAD E HIGIENE EN EL TRABAJO (2011). Plan Nacional de Formación en Prevención de Riesgos Laborales. Propuestas para el desarrollo de la Estrategia Española de Seguridad y Salud en el Trabajo 2007-2012 en materia de formación en prevención de riesgos laborales. [En línea]

http://www.insht.es/InshtWeb/Contenidos/

Instituto/Noticias/Noticias_INSHT2011/ficheros/PlanNacionalFormaci\%C3\%B3nP RL .pdf

- INSTITUTO NACIONAL DE SEGURIDAD E HIGIENE EN EL TRABAJO (2012). Estrategia Española de Seguridad y Salud en el Trabajo 2007-2012. Plan de acción para el impulso y ejecución de la Estrategia Española de Seguridad y Salud en el Trabajo 2007-2012. [En línea]

http://www.insht.es/InshtWeb/Contenidos/Instituto/Estrategia_Seguridad _Salud/Doc.Estrategia\%20actualizado\%202011\%20ultima\%20modificacion.pdf

- INSTITUTO NACIONAL DE SEGURIDAD E HIGIENE EN EL TRABAJO (2013). Balance final de la Estrategia Española de Seguridad y Salud en el Trabajo 2007-2012. [En línea]

http://www.insht.es/InshtWeb/Contenidos/Instituto/Comision/GruposTrabajo/ficher os/ Balance\%20FINAL\%20EESST.pdf

- INSTITUTO NACIONAL DE SEGURIDAD E HIGIENE EN EL TRABAJO (2015). Estrategia Española de Seguridad y Salud en el Trabajo 2015-2020. Madrid: Autor.

- LÓPEZ INSUA, B.M. (2014). "La prevención de riesgos laborales a escena: un desafío para los nuevos sistemas de metodología docente”. En ABOUSSI, M. (Coord.), DÍAZ AZNARTE LÓPEZ, M.T. y GRANADOS ROMERA, M.I. (Dirs.). Prácticas de innovación docente en ciencias sociales y jurídicas, pp. 143-148.

- MONEREO PÉREZ, J.L. y MOLINA NAVARRETE, C. (2004). “¿Qué hay de la famosa cultura de la prevención?” En MONEREO PÉREZ, J.L. Comentario a la Ley de Prevención de Riesgos Laborales y sus desarrollos reglamentarios. Granada: Comares.

- MONEREO PÉREZ, J.L. y LÓPEZ INSÚA, B.M. (2016). "El derecho a la prevención: un análisis del modelo organizativo preventivo español". Estudios financieros. Revista de trabajo y seguridad social: Comentarios, casos prácticos, recursos humanos, 395, 17-38.

- MORA, J.G. (2009). "Las políticas europeas de educación superior. Su impacto en España”. Papeles de economía española, 119, 263-276. 
- PÉREZ MERLOS, R. (2017). Análisis sobre la formación en prevención de riesgos laborales en España: Luces y sombras. [En línea] https://diagnosticoprlconstruccion. files.wordpress.com/2017/06/libro-formacic3b3n-documento-final-19 -6-2017blog.pdf

- VALDEOLIVAS GARCÍA, Y. y TUDELA CAMBRONERO, G. (s.f.). El Informe Durán sobre riesgos laborales y su prevención. Notas para un debate necesario. [En línea]

https://www.fraternidad.com/es-ES/download/el-informe-duran-sobre-riesgoslaborales-y-su-prevencion-notas-para-un-debate-necesario 